\title{
EFFECT OF DIAGONAL FORMATION OF PLATE PERFORATIONS ON THE TYROL WEIR DISCHARGE COEFFICIENT VALUE
}

\author{
*Nanang Saiful Rizal ${ }^{1}$, Nely Ana Mufarida², Kosjoko² \\ ${ }^{1}$ Department of Civil Engineering, University of Muhammadiyah Jember, Jl Karimata 49, Jember, Indonesia \\ ${ }^{2}$ Department of Mechanical Engineering, University of Muhammadiyah Jember, Jl Karimata 49, Jember, \\ Indonesia
}

*Corresponding Author, Received: 27 Aug. 2021, Revised: 10 Oct. 2021, Accepted: 17 Oct. 2021

\begin{abstract}
The purpose of this research is to find the equation of discharge coefficient (Cd) on a tyrol weir with diagonal circle filter sieve holes. To determine the discharge coefficient (Cd) a physical model test was conducted in laboratory by creating an open channel with a width of $40 \mathrm{~cm}$ and a length of $797 \mathrm{~cm}$. Hole variations were made with diagonal formations with diameters of $6,8,10$ and $12 \mathrm{~mm}$, screen slope $\theta=20^{\circ}$ $45^{\circ}$ and flowrate $Q=453-4481 \mathrm{~cm}^{3} \cdot \mathrm{s}^{-1}$. The physical test showed that the water flow for the diagonal holes was about $140 \%$ more than forthe screen with a straight formation of holes. The value of the discharge coefficient $(\mathrm{Cd})$ constant is directly proportional to the froude number $(\mathrm{Fr})$, the slope of the filter $(\theta)$, the ratio between the distance of the filter to the hole diameter (x/d) and inversely proportional to the specific energy (E). The value of the discharge coefficient constant is directly proportional to the Froude number, the slope of the filter, the ratio between the distance of the filter with the hole diameter and inversely proportional to the specific energy. After analysis, the results obtained that the value of the discharge coefficient constant (Cd) ranges between 0.15-2.75, then the accuracy of the model test obtained $R M S E=0.096, M A E=0.074, N S E=$ 0.836 .
\end{abstract}

Keywords: Tyrol weir, Diagonal Formation Screen, Circular Perforated Plate, Discharge Coefficient

\section{INTRODUCTION}

Agricultural land downslope from a volcano is typically fertile land, but the flow of irrigation water is sometimes blocked because the flow of water in the river contains rocks and sand. If the screen is clogged, and the distribution of water to the irrigation area decreases, it will reduce the productivity of agricultural businesses, especiallyin extreme climate conditions. Therefore, appropriate efforts are needed in water management for irrigation and other activities [1]. In some ceses there is a decrease in the groundwater level, in future it is necessary to make various efforts in the use of irrigation and other activities [2]. For water flows in rivers containing small and large size sediments [3], there needs to be a solution so that they can be tapped into irrigation channels by making tyrol dams. To increase the capacity of water uptake and filtering of sediment using a maze weir with geometric shapes triangles, trapezoids and rectangles [4]. Sediment that cannot be filtered apart from clogging can also reduce the capacity of the conduit [5].

A tyrol weir is made for debris flow which is usually in rivers that are under active mountains [6], steep riverbed slope and irregular water flow configuration [7]. The screen is tilted using a screen rod to break the flow and absorption of energy. A water extraction system using tyrol weir can prevent stones from entering the screen. Even though there is a screen, it can capture up to $80 \%$ of water. For application in the field, the current value coefficient of discharge constant (Cd) uses the equation on a plate with a straight formation circle hole only. So in the future it is necessary to analyze the value coefficient of discharge constant (Cd) in diagonal formation circle hole. in making the equation of the coefficient of discharge coefficient (Cd) cross formation it is necessary to consider the slope factor of the screen, the screen length and the distance between the screens so that the $\mathrm{Cd}$ value to be obtained can be applied in the field in tyrol weir, flow conditions are very influential on water catchment. Flow conditions can generally be known from the value of the froude number.

Froude numbers can be used as indicators to determine the level of energy dissipation in the tyrol weir. In streams with small froude numbers (subcritical flow) [8], the value coefficient of discharge is influenced with screen length (L), screen area of opening $(\varepsilon)$, the ratio screen distance, hole width (s). From the results of previous study, the coefficient of discharge flow subcritical conditions with several factors, including screen width (s), hole width (L) and the degree of slope of 
the screen $(\theta)$. From the physical model test results, it was also obtained that Cd was affected by the screen length, screen slope and screen depth [9].

After a complete study of tvulcahe hydraulic flow behavior of the screen [10], a result was obtained, namely that the discharge coefficient is strongly influenced by the distance between screens, screen thickness $(t)$, and screen slope $(\theta)$. In one study, it was found that the screen slope value of the screen discharge coefficient (Cd) a slope is between $20-45 \%$. The discharge coefficient ranges from 0.35 to 0.90 . The value of $\mathrm{Cd}$, the shape of geometric screen was initially ignored, including in other studies also suggesting that the value of $\mathrm{Cd}$ needs to take into account the flow conditions with the amount of discharge entering screen [8]. In another study, at a slope of $20-45 \%$ the coefficient of disposal was about 0.35-0.90. In another study case, it is recommended that the amount of $\mathrm{Cd}$ also considers the number of holes in the screen including the conditions of flow [8].

In previous studies, the value of $\mathrm{Cd}$ has been obtained on a circular perforated plate using a straight formation, obtained the results of Cd values between 1.0-2.75. However, for the purposes of field application, it is necessary to consider the diagonal sieve hole formation because the material available in the field is diagonal formation. The physical model test and the study were conducted to obtain the value of the coefficient of discharge (Cd) on the screen with diagonal formation perforated plates with a number of variations in discharge, hole diameter, distance between holes and slope of the screen.

In order to obtain any factors that influence the value of $\mathrm{Cd}$ with diagonal formation, which in general of $\mathrm{Cd}$ is also influenced by the screen length [11], [12]. This research is very significant because currently many tyrol weirs are using steel filter rods replaced with circular perforated plates, while the discharge coefficient is still using steel filter rods. So if this is still used of course the results are not accurate for planning purposes.

\section{RESEARCH SIGNIFICANCE}

The mountainous area has very fertile land but on the one hand the river water that is taken sometimes contains sediment. Tyrol weirs equipped with screens are needed so that river water can be channeled into agricultural land without containing sediment. Screens with circular perforated plates are more effective at filtering sediment than steel filter rods. However, for field applications, a formula or equation is needed to calculate the discharge that enters the filter.

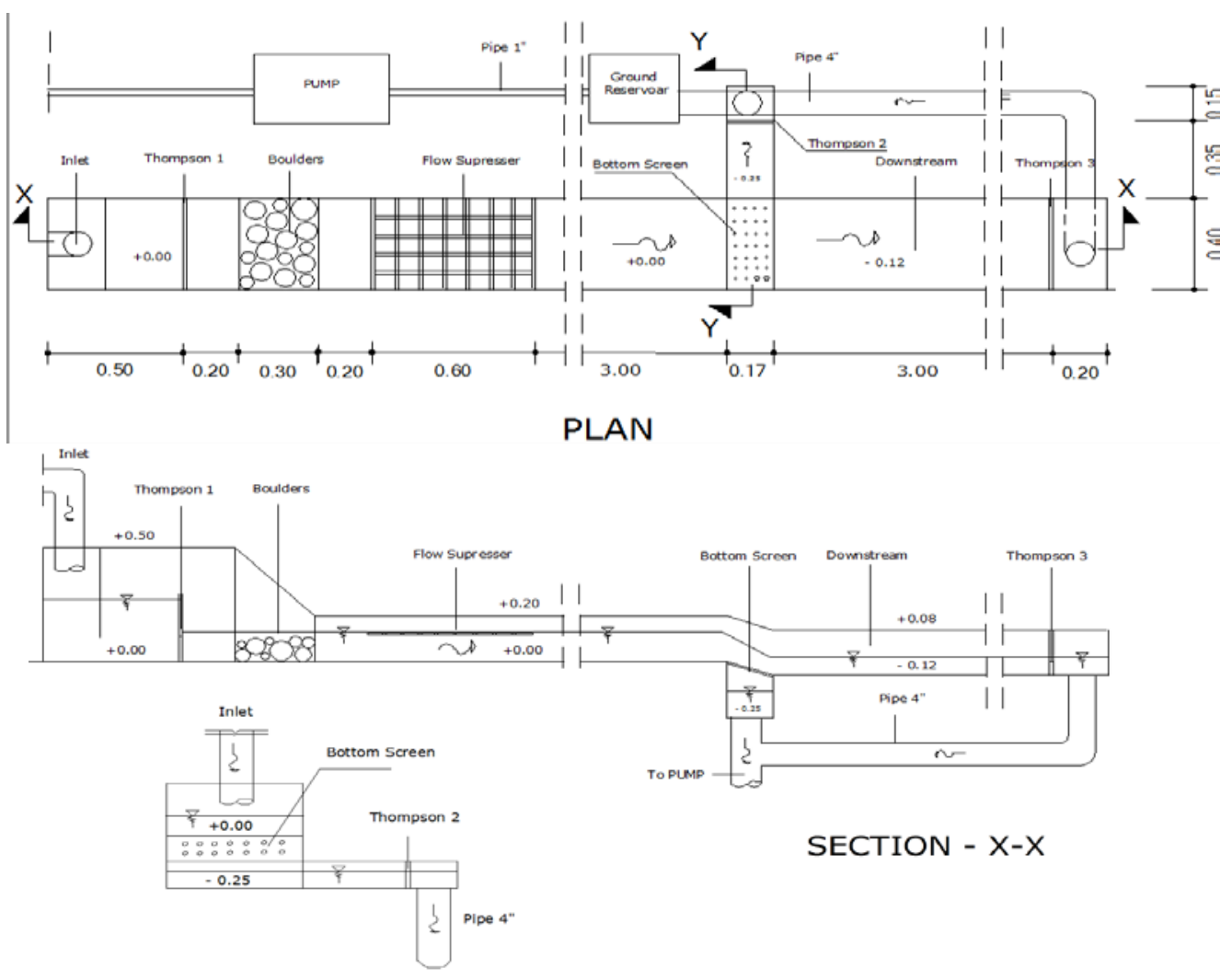

Fig.1 Settings for the tyrol weir equipment in the water resources engineering laboratory: in meters 


\section{METHODOLOGY}

In searching for the equation coefficient of discharge constant (Cd) on a sieve using a diagonal formation perforated plate, a physical model was made at the Open Hydraulics Test Laboratory, Water Resources Engineering, Brawijaya University, with the description of activities : Designing a physical model test in the form of water flow from upper reservoir into the inlet and insert it into channel, part of it goes into the screen and part of it enters the outlet as presented in Figure 1.

Water from reservoir enters to the inlet and the channel, part of which enters screens and outlets flow into lower reservoir, from the lower reservoir and pump a capacity of $20 \mathrm{dm}^{3} \mathrm{~s}^{-1}$ to the upper reservoir. The Thompson gauge is mounted on a triangular threshold that serves to measure the discharge that will enter the channel, enter the screen and enter the outlet. A sieve of an iron plate with a plate thickness of $\mathrm{t}=0.05 \mathrm{~mm}$ was then given a hole with various variations of the diameter of the hole and various variations of the screen slope. In each variation of the diameter of the hole with the slope of the screen made 8 treatment variations in flowrate. A point gauge is installed in the middle of the channel and downstream of the channel to measure the height of the water in the channel.

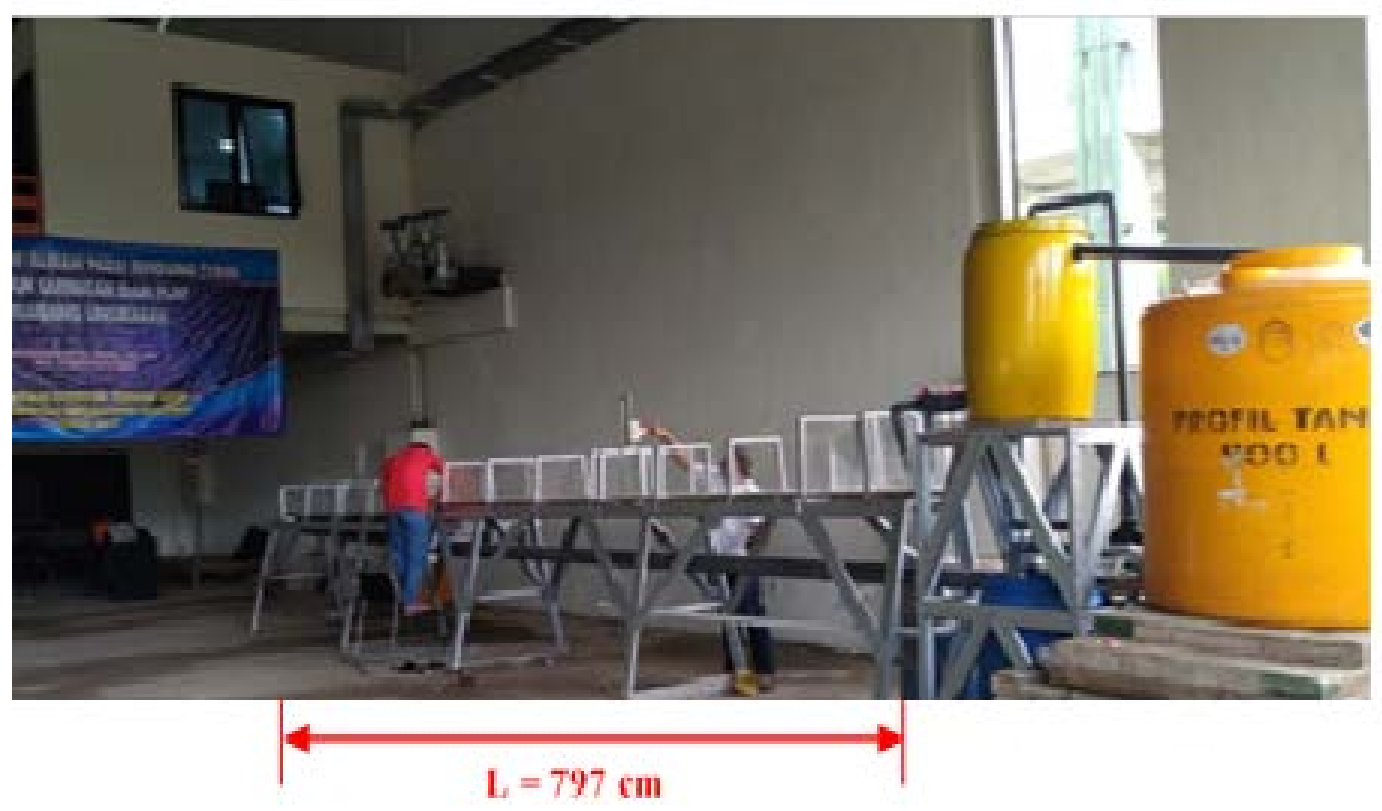

Fig.2 Physical model of open channel to get the discharge coefficient constant (Cd)
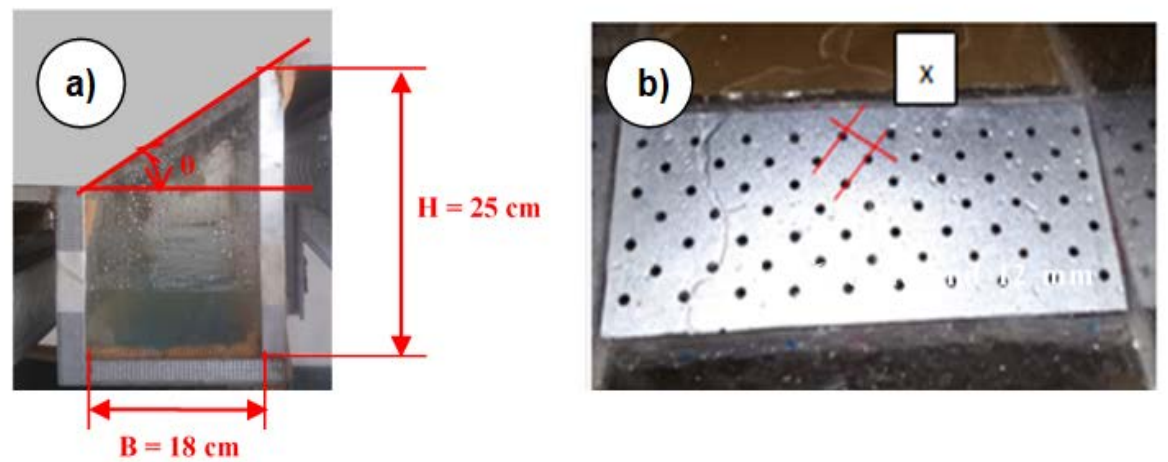

Fig.3 Sieve tilt position and screen hole formation: a) conduit, b) plate with circular holes 
Table 1 Coefficient of discharge (CD), $\theta_{1}=20^{\circ}$ with ratio $\mathrm{x}$ : $\mathrm{d}=5.667$

\begin{tabular}{ccccccccc}
\hline $\begin{array}{c}Q_{\text {inflow }} \\
\mathrm{cm}^{3} \cdot \mathrm{s}^{-1}\end{array}$ & $\begin{array}{c}Q_{\text {obs-tyrol }} \\
\mathrm{cm}^{3} \cdot \mathrm{s}^{-1}\end{array}$ & $\omega$ & $\begin{array}{c}v \\
\left(\mathrm{~cm} \cdot \mathrm{s}^{-1}\right)\end{array}$ & $\mathrm{Fr}$ & $\begin{array}{c}H c \\
\mathrm{~cm}\end{array}$ & $\begin{array}{c}E \\
\mathrm{~cm}\end{array}$ & $\begin{array}{c}Q_{\text {calc-tyrol }} \\
\left(\mathrm{cm}^{3} \cdot \mathrm{s}^{-1}\right)\end{array}$ & $C d$ \\
\hline 221 & 186 & 0.015 & 11.04 & 0.499 & 0.010 & 0.016 & 50 & 3.747 \\
453 & 221 & 0.015 & 18.89 & 0.779 & 0.044 & 0.065 & 102 & 2.169 \\
792 & 280 & 0.015 & 30.47 & 1.207 & 0.133 & 0.200 & 178 & 1.575 \\
1250 & 302 & 0.015 & 44.63 & 1.703 & 0.332 & 0.497 & 281 & 1.076 \\
1837 & 325 & 0.015 & 57.41 & 2.049 & 0.717 & 1.075 & 413 & 0.787 \\
2565 & 453 & 0.015 & 71.25 & 2.398 & 1.397 & 2.096 & 576 & 0.787 \\
3443 & 512 & 0.015 & 78.26 & 2.382 & 2.518 & 3.777 & 773 & 0.662 \\
\hline \multicolumn{7}{c}{ Average } \\
\hline \multicolumn{7}{c}{}
\end{tabular}

\section{RESULTS AND DISCUSSIONS}

Calculations are performed to obtain the value coefficient of discharge $(\mathrm{Cd})$ that enters the screen due to changes in diameter and diagonal distance between screens $(\mathrm{x}: \mathrm{d})$ at various screen diameter variations, screen slope and flow in channel. As explained in the previous chapter this calculation is done with several variations :

Screen diameter : $\mathrm{d}=6 \mathrm{~mm}, 8 \mathrm{~mm}, 10 \mathrm{~mm}$ and $12 \mathrm{~mm}$. Screen slope : $\theta_{1}=20^{\circ}, \theta_{2}=25^{\circ}, \theta_{3}=30^{\circ}$ and $\theta_{4}=45^{\circ}$. Flow rate that follows the measurement of the height of water above the thompson building ( $\mathrm{T} 1=3 \mathrm{~cm}$ to $10 \mathrm{~cm}$ ). The complete calculation results are presented in the appendix, while some of the calculation results on the $20^{\circ}$ screen slope are presented in table 1 .
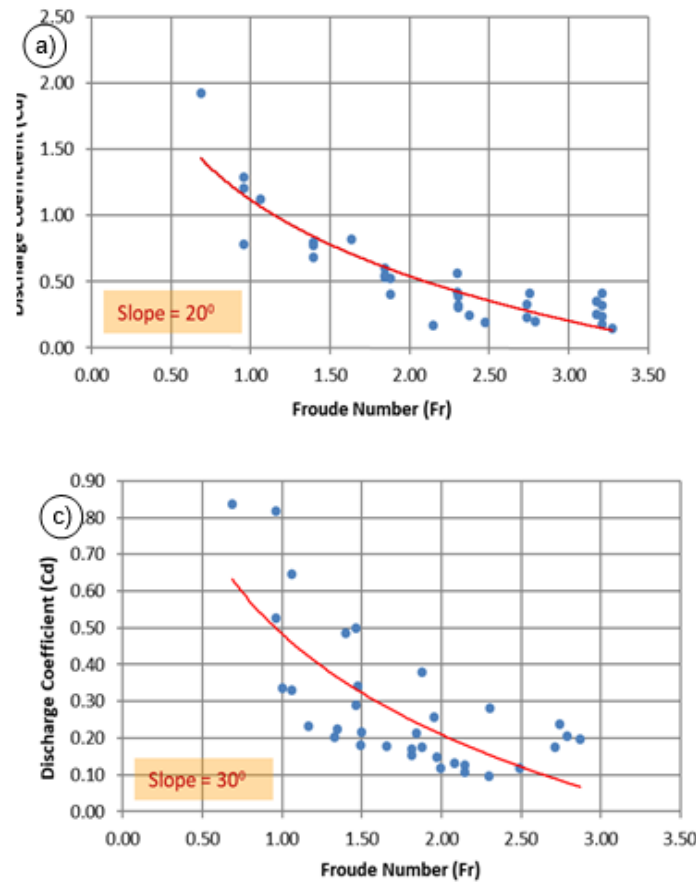

The physical model test results in Figure 4 are seen when the value of the number of froude ranges from 0.20 to 2.75 , obtained the value of Cd between 0.10 - 1.95. Cd values trend to decrease at the slope of the screen $\theta_{1}=20^{\circ}, \theta_{2}=25^{\circ}, \theta_{3}=30^{\circ}$, but tend to increase at the slope of the screen $\theta_{4}=45^{\circ}$. However, the increase in $\mathrm{Cd}$ value is not as significant as on the screen tilt $\theta_{1}=20^{\circ}$ and $\theta_{2}=$ $25^{\circ}$. Means there are other factors that influence the value of the discharge coefficient in addition to the number froude. Although the value of the discharge coefficient goes up and down, the trend of the relationship between the value of the discharge coefficient and the number froude tends to follow the equation of logarithmic a correlation level of $\mathrm{R}$ $=60-75 \%$.
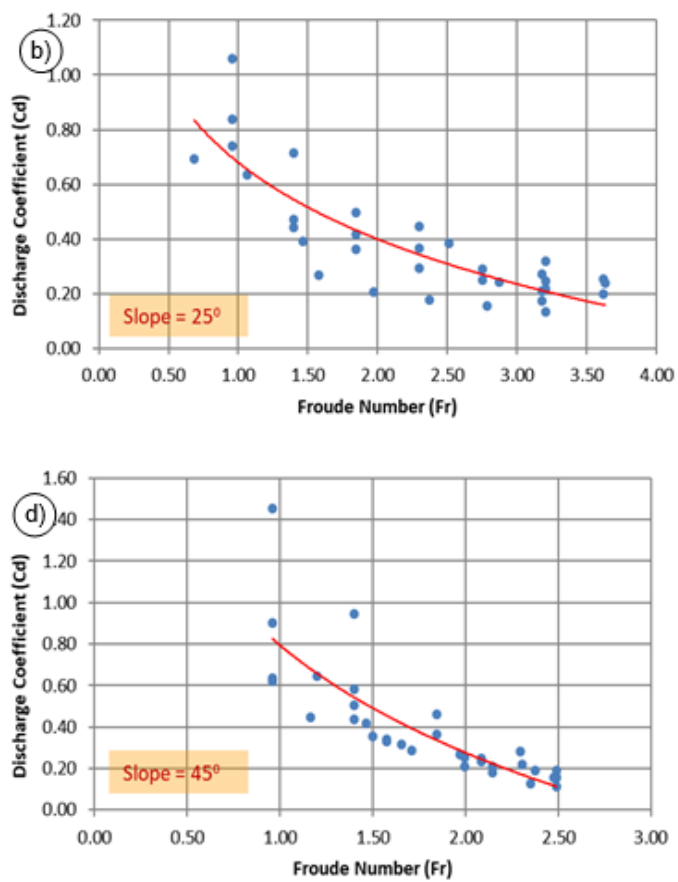

Fig.4 Relationship between discharge coefficient $(C d)$ and Froude Number (Fr) at $d_{1}=6 \mathrm{~mm}, d_{2}=8 \mathrm{~mm}, d_{3}=$ $10 \mathrm{~mm}$ and $d_{4}=12 \mathrm{~mm}$ on screens slope: a) $\theta_{1}=20^{\circ}$, b) $\theta_{2}=25^{\circ}$, c) $\theta_{3}=30^{\circ}$, d) $\theta_{4}=45^{\circ} ; d=$ the hole diameter 

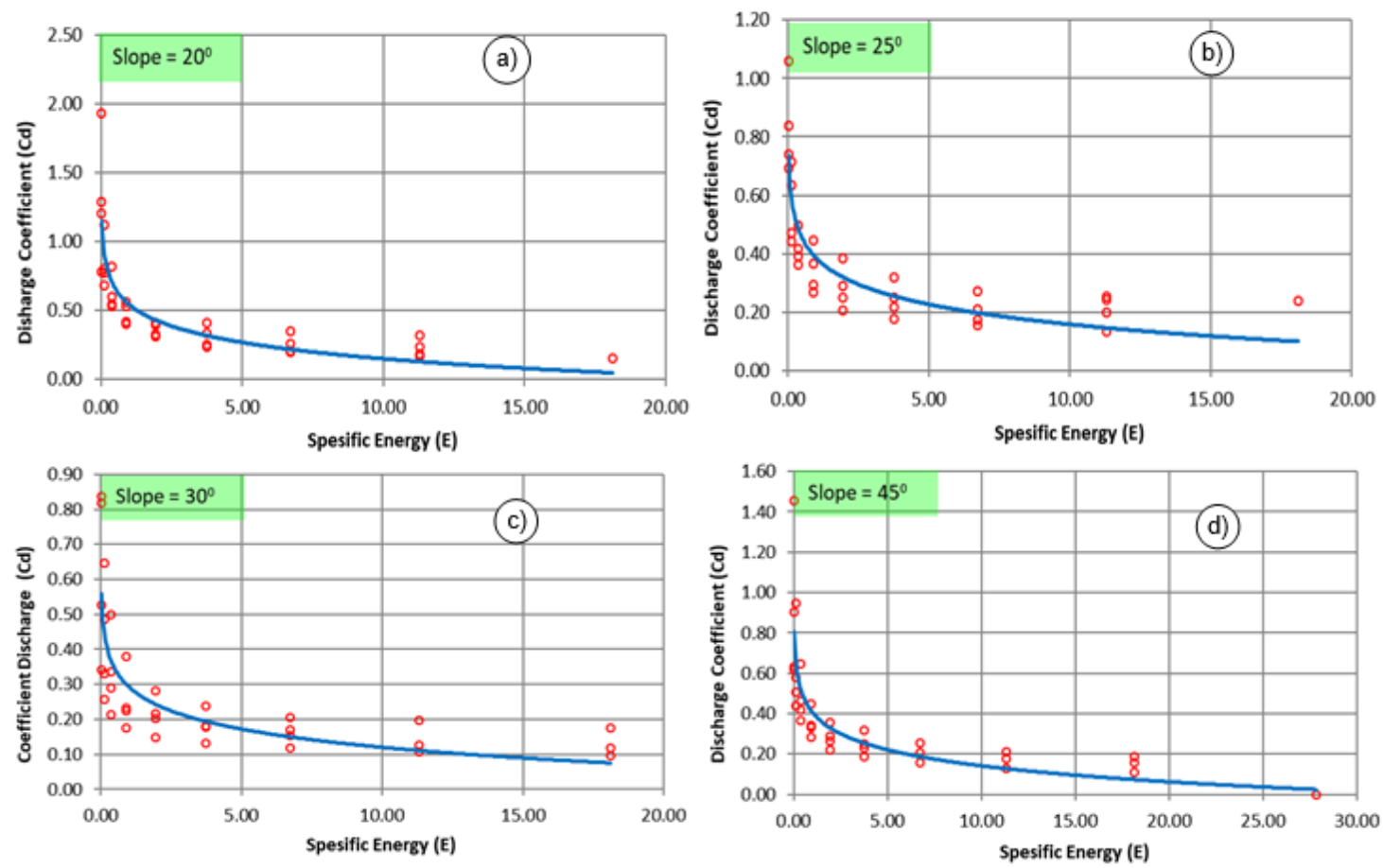

Fig.5 Relationship between spesific energy (E) and discharge coefficient $(C d)$ at $d_{1}=6 \mathrm{~mm}, d_{2}=8 \mathrm{~mm}, d_{3}=$ $10 \mathrm{~mm}$ and $d_{4}=12 \mathrm{~mm}$ on screens slope: a) $\theta_{1}=20^{\circ}$, b) $\theta_{2}=25^{\circ}$, c) $\theta_{3}=30^{\circ}$, d) $\theta_{4}=45^{\circ} ; d=$ the hole diameter; source: own study

From the results of the physical model test as shown in Figure 5, that when the specific energy value $(\mathrm{E})$ ranges between $0.065-27.517 \mathrm{~cm}$, the value of Cd ranges between $0.20-2.75$. The specific energy value is inversely proportional to the value of the discharge coefficient, this result is in accordance with previous studies [7]. In general, Cd and $\mathrm{E}$ follows the relationship of algorithmic functions with a correlation value of $\mathrm{R}$ between 44$87 \%$. The highest correlation coefficient value is in the $45^{\circ}$ screen slope of 0.582 while the lowest value in the $30^{\circ}$ screen slope is 0.482 . At the $30^{\circ}$ screen tilt, there is more outline of the data than at the $20^{\circ}$ and $25^{\circ}$ screen tilt. Likewise, on the slope of the $45^{\circ}$ screen there is also an outline of data but not as much as on the $30^{\circ}$ screen tilt. In general, this is due to inadequate measurement accuracy and limited conditions of the equipment used when testing the physical model. Besides the above factors are also influenced by variations in flow rates that are sometimes not constant. Based on the description above, in general froude numbers and specific energy greatly affect the value of the discharge coefficient. But it needs to be reviewed again for other factors that might influence the $\mathrm{Cd}$ value as the results of previous studies, including how the influence of the slope of the screen, the effect of the shape of the screen formation and the influence of the hole diameter and the distance screen holes. For the screen slope, the value $\theta$ is expressed in $\cos \theta$ [6].
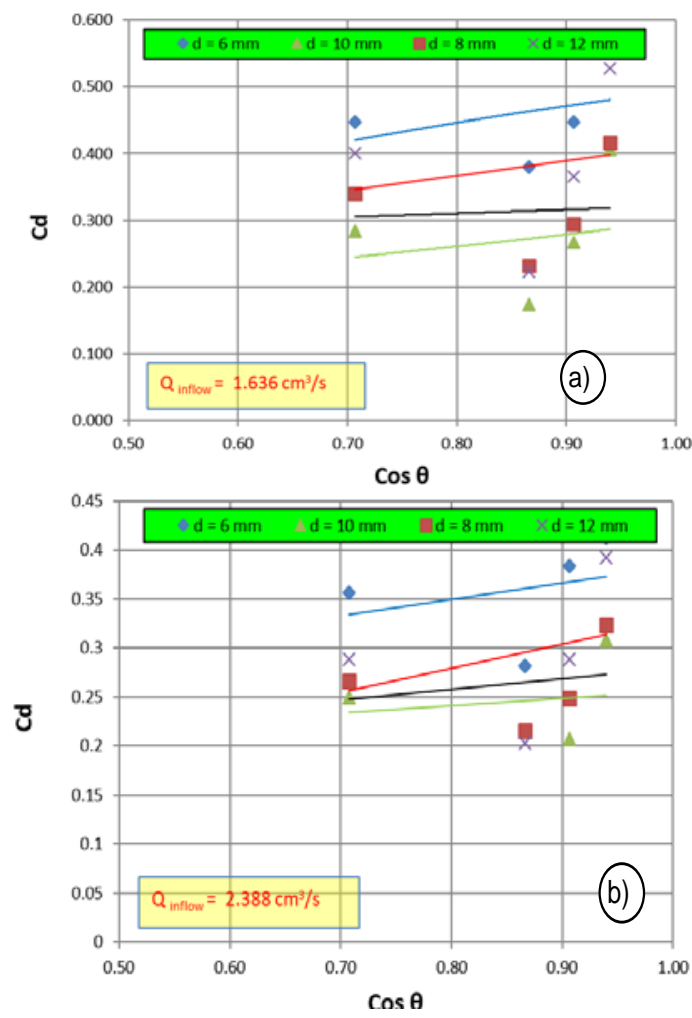

Fig.6 Relationship between slope $(\cos \theta)$ and discharge coefficient $(C d)$ at different discharge: a) $Q=1636 \mathrm{~cm}^{3} \cdot \mathrm{s}^{-1}$, b) $Q=2388 \mathrm{~cm}^{3} \cdot \mathrm{s}^{-1}$ 
As shown in Figure 6, the greater the sreen slope $(\theta)$, discharge coefficient $(\mathrm{Cd})$ is lower, and the larger diameter hole $(\mathrm{d})$, discharge coefficient $(\mathrm{Cd})$ decreases. In Figure 7, it also shows that when the inrush current is $1,636 \mathrm{~cm}^{3} . \mathrm{s}^{-1}$ and the slope of the screen $\theta_{1}=20^{\circ}$ the value of $\mathrm{Cd}$ from 0.19 to 0.52 . The inflow $2,388 \mathrm{~cm}^{3} \cdot \mathrm{s}^{-1}$ and the slope of the screen $\theta_{1}=20^{\circ}$, Cd from 0.20 to 0.39 . These results indicate that the value $\mathrm{Cd}$ influenced with screen slope and hole diameter. Each diameter (d) hole is separated a certain diagonal distance $(\mathrm{x})$, so needs to be studied how the influence of relationship between the discharge coefficient with the ratio $\mathrm{x}$ : d. In general the value of the $\mathrm{Cd}$ is greatly influenced the value of the discharge coefficient. Hole dimensions are also related to the diagonal distance between holes. Then the relationship between the hole diameter (d) and the distance of the diagonal hole $(x)$ is expressed in the form between $\mathrm{x}: \mathrm{d}$.
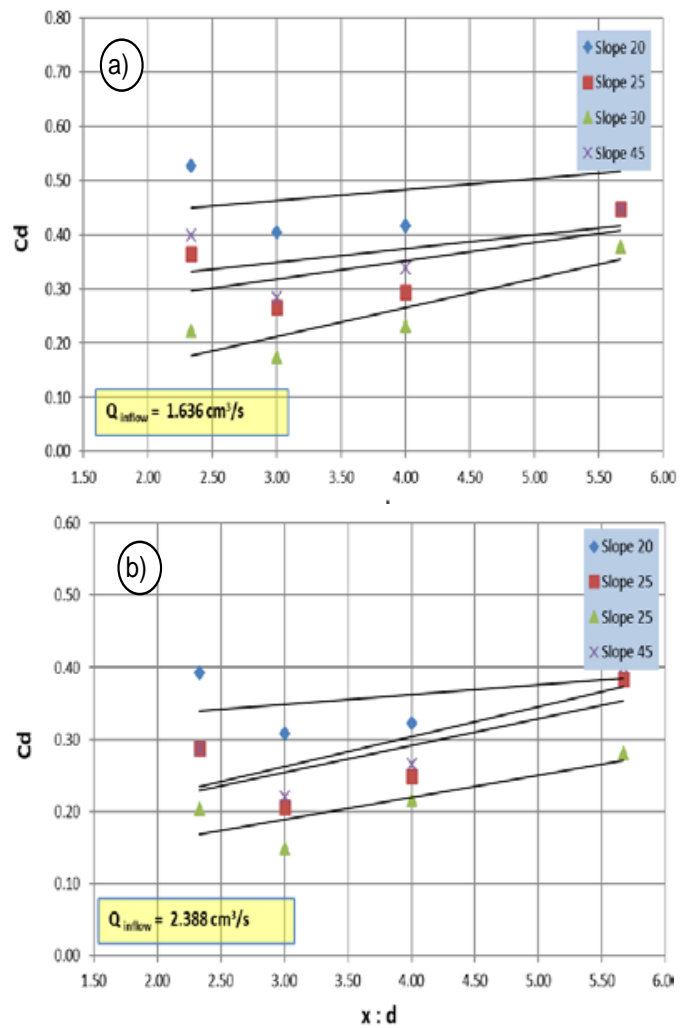

Fig.7 Relationship between ratio of distance with hole diameter (a:d) of screen at discharge of different and discharge coefficient (Cd) : a) $\mathrm{Q}=1$ $636 \mathrm{~cm}^{3} \cdot \mathrm{s}^{-1}$, b) $\mathrm{Q}=2388 \mathrm{~cm}^{3} \cdot \mathrm{s}^{-1}$

The discharge coefficient increases when the a: $\mathrm{d}$ ratio gets higher as shown in Figure 7 . However, when a: $d=4$ and the screen slope is $25^{\circ}$, the discharge coefficient value reaches the lowest point (if $\mathrm{Q}=1636 \mathrm{~cm}^{3} \cdot \mathrm{s}^{-1}$ then value $\mathrm{Cd}=0.35$, if $\mathrm{Q}=$ $2388 \mathrm{~cm}^{3} \cdot \mathrm{s}^{-1}$ then the value of $\mathrm{Cd}=0.28$ ). At a $45^{\circ}$ screen tilt, the $\mathrm{Cd}$ value rises but is not very significant. If the a: $\mathrm{d}$ ratio is greater, value of $\mathrm{Cd}$ will be even greater. This shows that the hole diameter including the diagonal distance between the screen holes really affects the discharge coefficient value on the circular perforated plate which has a diagonal screen formation.

As previously described, it explained that the value of $\mathrm{Cd}$ is strongly influenced the specific energy quantity (E), Froude number ( $\mathrm{Fr}$ ), screen slope $(\cos \theta)$, hole spacing ratio and diameter ratio (x:d). Almost the same as a straight formation screen, the diagonal formation relationship between $\mathrm{Cd}$ and $\mathrm{E}$ and Fr follows the logarithmic function, while the relationship between Cd with $\mathrm{x}$ : $\mathrm{d}$ and $\cos$ $\theta$ follows the quadratic function. So to get the level of relationship between the variables mentioned above, it is necessary to do a statistical test of the relationship $C d$ to the values of $E, \cos \theta, F r$ and $x: d$. $\mathrm{Cd}$ with respect to $\mathrm{E}, \mathrm{Fr}, \theta$ and $\mathrm{a}$ : $\mathrm{d}$ has a significant relationship as presented in table- 1 , with the value of $\mathrm{R}=0.909$, $\mathrm{R} 2=0.826$.

As previously stated [6], [10], the value of Cd strongly influenced the value of Fr, $\mathrm{E}$ and screen slope to the host area. Then the equation modeling to show the relationship between $\mathrm{Cd}$ to $\mathrm{Fr}, \mathrm{E}, \theta$ with $\mathrm{a}$ : $d$ the values of the variables mentioned above can be entered. Adaptation to the relationship between variables can be done by taking all the data or most of the physical model test results on various forms of screen formations with various hole diameters and slopes (140 data series). As presented in Table 6 , that is, the screen slope is $25^{\circ}$ and $30^{\circ}$ and the screen diameter is $8 \mathrm{~mm}$ and $10 \mathrm{~mm}$.

An empirical model of release $\mathrm{Cd}$ created a screen with flat circular pallet on the diagonal formation is presented in table 1 and follows the following equation function :

$C d=\frac{0,238 \cdot F r^{0.152} \cdot \operatorname{Cos} \theta^{0.319} \cdot x / d^{0.392}}{E^{0.287}}$

This result can only be applied to sub-critical flow conditions by forming between a straight shape of hole with screen slope $20^{\circ}$ and $45^{\circ}$. This result has a fairly good level of accuracy with NSE $=0.836$, MAE $=074$ and RMSE $=0.096$.

This performance test is carried out to review how the performance of the percentage of water discharge that enters the filter in both diagonal and straight formations. To see this performance will be compared between the inflow discharge with the tryrol discharge at various discharge variations and various variations of the filter slope. To do this, it is necessary to make a rating curve for the relationship between $\mathrm{H}$ and $\mathrm{Q}$ on 4 variations of the sieve slope, then calculate the amount of discharge entering the tyrol weir, either on a straight or diagonal sieve. The rating curve is presented in Figure 8 . The rating 
curve was made based on the results of physical model tests on various discharge variations and various hole diameter variations with a total of 32 trials data.

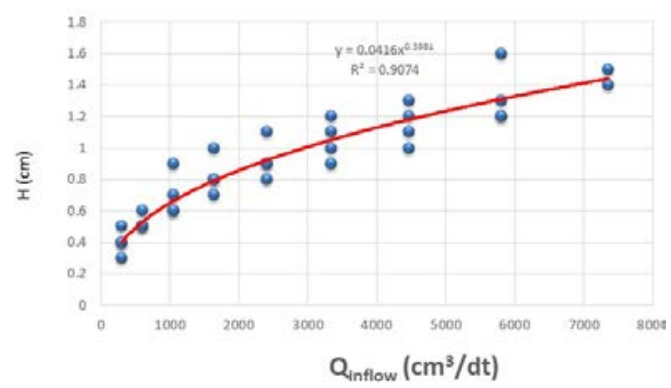

Fig 8. Graph of relationship Q inflow with $\mathrm{H}$ above the weir

Water level profile above the filter with cross formation In Figure 9 it can be seen that with various variations of different inflow discharges entering the filter with a slope of $20^{\circ}$ both with diagonal formations and straight formations, it turns out that the diagonal formation has the ability to enter more water into the tyrol weir than the straight formation. The more discharge that flows, the deviation is greater than the straight formation filter.
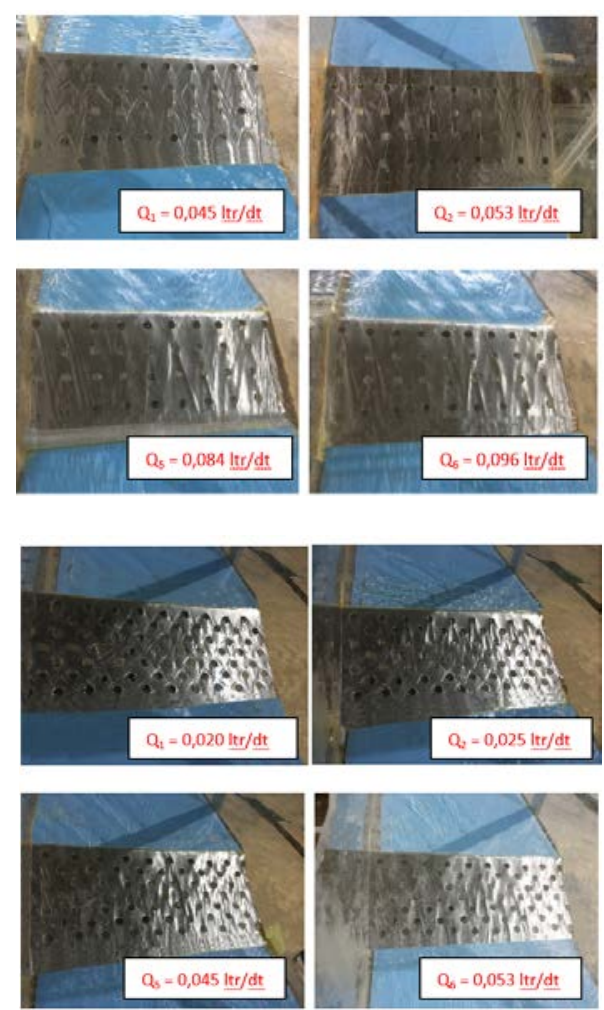

Fig.9. Water level profile above the filter with cross formation.

In Figure 8, it can be seen that with different variations of inflow discharge entering the sieve with a slope of $20^{\circ}$ both with diagonal formation and straight formation, it turns out that the diagonal formation has the ability to enter more water into the tyrol weir than the straight formation. The more discharge that flows, the deviation is greater than the straight formation filter. To monitor the performance of the 2 sieve formations, it can also be seen at the sieve slope of $25^{\circ}, 30^{\circ}$ and $45^{\circ}$ then the results are presented in graphical form in Figure 9.
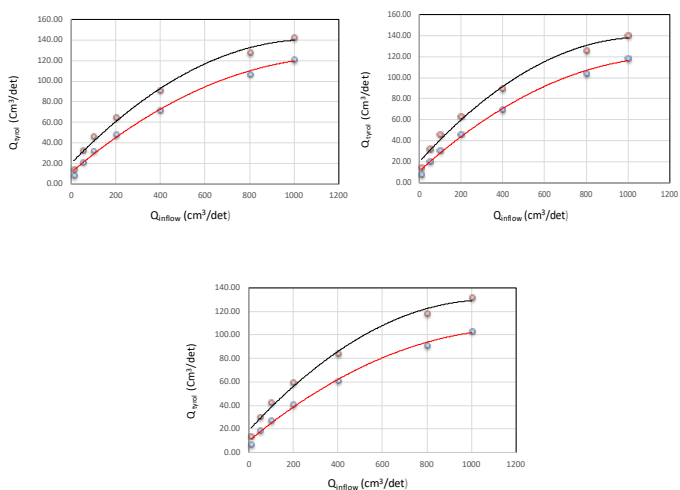

Fig 10. Performance comparison chart of straight and cross formation sieves at sieve slopes of $25^{\circ}$, $30^{\circ}$ and $45^{\circ}$.

From the results of monitoring the performance of straight and diagonal sieves at of $25^{\circ}, 30^{\circ}$ and $45^{\circ}$ sieve slopes, it can be seen that the performance of all sieves with diagonal formations is better than straight formations. The lower the sieve slope, the better the sieve formation performance.

\section{CONCLUSIONS}

Tyrol weirs that use diagonal formation screens are more effective when compared to straight formations in capturing water. Through a test of a diagonal form of physical model, the results show that the influencing factor is the hydraulic flow, namely: the amount of discharge entering the conduit represented by the value $\mathrm{Cd}$. The value of $\mathrm{Cd}$ is strongly influenced the froude number $(\mathrm{Fr})$, the specific energy ratio $(E)$ between the screen distance with the hole diameter (x: d) and the screen slope $(\theta)$.

The discharge coefficient (Cd) on a tyrol weir which has a diagonal formation screen states that the $\mathrm{Cd}$ is inversely proportional to specific energy factor (E), is directly proportional to the froude number $(\mathrm{Fr})$, screen slope $(\theta)$, distance ratio and hole diameter ( $\mathrm{x}$ : d). For the purposes of field applications, especially in subcritical flow conditions by forming a straight shape of hole and tilt of the screen $20^{\circ}$ to $45^{\circ}$. The results of this modeling have a relatively good level of accuracy, indicated by the values of NSE $=0.836$, $\mathrm{MAE}=074$ and $\mathrm{RMSE}=0.096$. 


\section{REFERENCES}

[1] Łabędzki, L., Expected development of irrigation in Poland in the context of climate change. Journal of Water and Land Development, Vol. 13, 2009, pp.17-29.

[2] Kowalczyk-Juśko, A., Mazur. A., Grzywna, A., Listosz, A., Rybicki, R., Pytka, A., Dorozhynskyy, O., Jóźwiakowski, K. \& Gizińska-Górna, M, Evaluation of the possibilities of using water-damming devices on the Tyśmienica River to build small hydropower plants. Journal of Water and Land Development, Vol. 35, Issue 1, 2017, pp.113119.

[3] Bąk, L. \& Dąbkowski, S.L., Spatial distribution of sediments in Suchedniów reservoir. Journal of Water and Land Development, Vol.19, Issue 1, 2013, pp.13-22.

[4] Le, AT., Hiramatsu, K., Nishiyama, T., Hydraulic Comparison Between Piano Key Weir and Rectangular Labyrinth Weir. International Journal of GEOMATE, Vol.20, Issue 82, pp.153-160.

[5] Soekarno, I., Farid, M., Oriandra, RD., Cirata Reservoir Lifetime Prediction Using New Hydrometrics and Sediment Approaches. International Journal of GEOMATE, Vol.18, Issue 65, pp. 41 - 48.

[6] Drobir, H., Kienberger V. \& Krouzecky, N., The wetted rack length of the tyrolean weir, in Proceedings of the 28 IAHR Conference, 1999, pp.1-9.
[7] Bouvard, M, Mobile barrages and intakes on sediment transporting rivers. Rotterdam: Balkema Publishers. 1992.

[8] Kumar, S., Ahmad, Z., Kothyari, U.C. \& Mittal, M.K., Discharge diversion characteristics of trench weirs. Flow Measurement and Instrumentation, Vol. 21, Issue 2, 2010, pp.80-87.

[9] Kamanbedast, A.A. \& Bejestan, M.S., Effects of slope and area opening on the discharge ratio in bottom intake structures. Journal of Applied Sciences, Vol.8, Issue 14, 2008, pp.2631-2635.

[10] Ghosh, S. \& Ahmad, Z., Characteristics of flow over bottom racks. Water and Energy International, Vol.63, Issue 2, 2005, pp.47-55.

[11] Nakagawa, H., On hydraulic performance of bottom diversion works. Bulletin of Disaster Prevention Research Institute, Vol.18, Issue 3, 1969, pp.29-48.

[12] Righetti, M., Rigon, R. \& Lanzoni, S., Indagine sperimentale del deflusso attraverso una griglia di fondo a barre longitudinali [Experimental investigation of outflow through a bottom grid with longitudinal bars]. Proceedings of the XXVII Convegno di Idraulica e Costruzioni Idrauliche, 3, 2000, pp.112-119.

Copyright (C) Int. J. of GEOMATE All rights reserved, including making copies unless permission is obtained from the copyright proprietors. 